This item was submitted to Loughborough's Research Repository by the author.

Items in Figshare are protected by copyright, with all rights reserved, unless otherwise indicated.

\title{
The impact of biodiesel on particle number, size and mass emissions from a
}

\section{Euro4 diesel vehicle}

PLEASE CITE THE PUBLISHED VERSION

http://dx.doi.org/10.4271/2010-01-0796

PUBLISHER

(C) SAE International

VERSION

VoR (Version of Record)

LICENCE

CC BY-NC-ND 4.0

\section{REPOSITORY RECORD}

Tinsdale, Mark, Phil Price, and Rui Chen. 2011. "The Impact of Biodiesel on Particle Number, Size and Mass Emissions from a Euro4 Diesel Vehicle”. figshare. https://hdl.handle.net/2134/8398. 
This item was submitted to Loughborough's Institutional Repository (https://dspace.lboro.ac.uk/) by the author and is made available under the following Creative Commons Licence conditions.

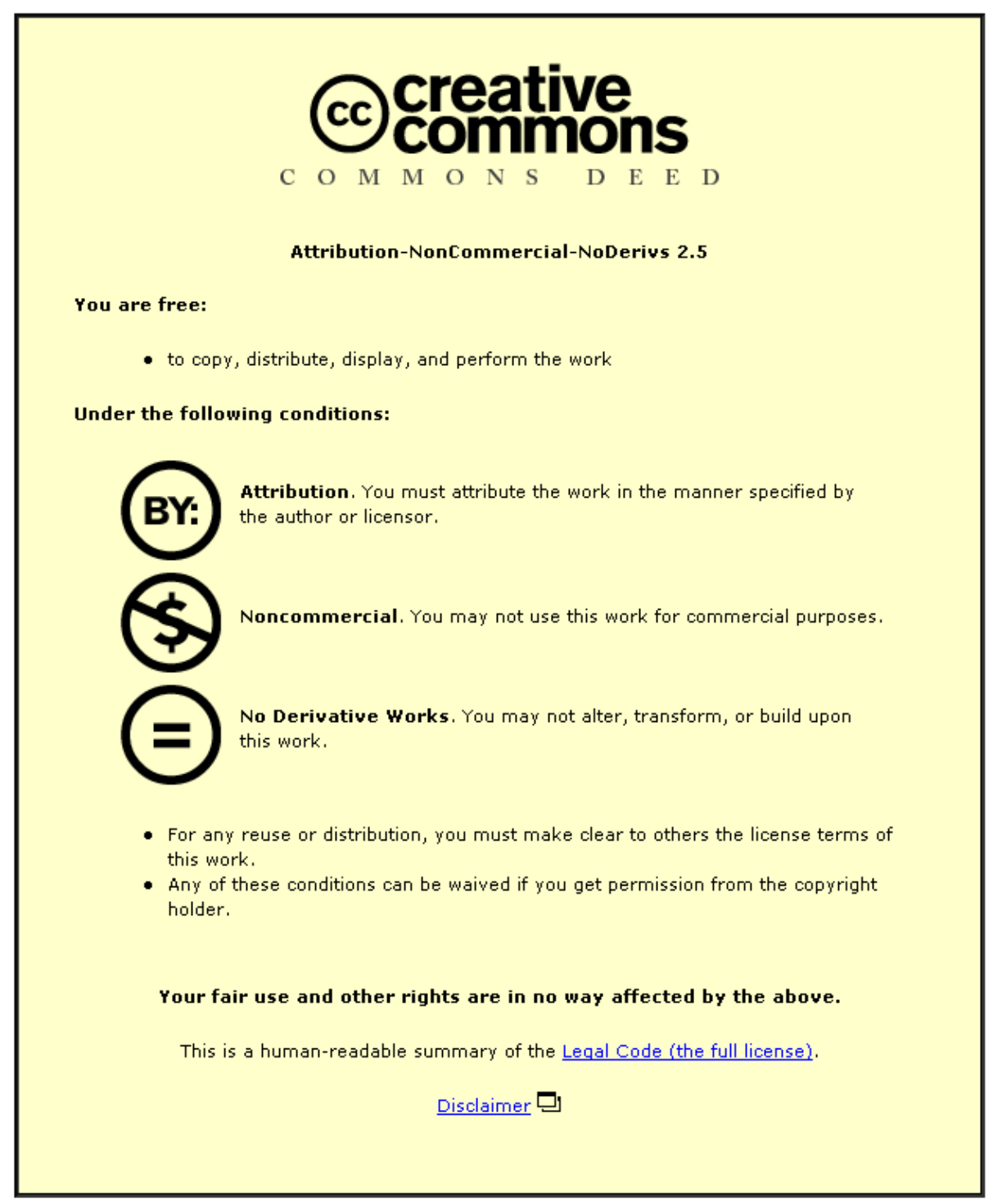

For the full text of this licence, please go to: http://creativecommons.org/licenses/by-nc-nd/2.5/ 


\title{
The Impact of Biodiesel on Particle Number, Size and Mass Emissions from a Euro4 Diesel Vehicle
}

\author{
Mark Tinsdale and Phil Price \\ Ford Motor Co. \\ Rui Chen \\ Loughborough Univ.
}

\begin{abstract}
New European emissions legislation (Euro5) specifies a limit for Particle Number (PN) emissions and therefore drives measurement of PN during vehicle development and homologation. Concurrently, the use of biofuel is increasing in the marketplace, and Euro5 specifies that reference fuel must contain a bio-derived portion.
\end{abstract}

Work was carried out to test the effect of fuels containing different levels of Fatty Acid Methyl Ester (FAME) on particle number, size, mass and composition. Measurements were conducted with a Cambustion Differential Mobility Spectrometer (DMS) to time-resolve sub-micron particles (5-1000nm), and a Horiba Solid Particle Counting System (SPCS) providing PN data from a Euro5-compliant measurement system. To ensure the findings are relevant to the modern automotive business, testing was carried out on a Euro4 compliant passenger car fitted with a high-pressure common-rail diesel engine and using standard homologation procedures.

It was found that using FAME decreased total PN emissions, by $16 \%$ over the Type I drive cycle (NEDC) for a $30 \%$ biodiesel (B30) compared to mineral fuel (B0). FAME also decreased accumulation mode PN and carbonaceous mass, by $20-30 \%$ for $\mathrm{B} 30$ versus $\mathrm{B} 0$, with a consequent reduction in Diesel Particulate Filter loading rate. A 25\% increase in the nucleation mode PN was found when using B 30 versus $\mathrm{B} 0$, and the higher molecular-weight organic mass fraction also increased. Increases in nitrogen oxides when using FAMEcontaining fuels were also confirmed.

\section{INTRODUCTION}

Introduction of a Particle Number (PN) limit in Euro5 emissions legislation, and the associated necessity for PN measurement, is driven by two things. Firstly, there are concerns over the resolution of the existing gravimetric technique for particulate mass measurement (PM), against a backdrop of ever-lower limits. Anticipating a point where the viability of this technique is questionable, confidence needs to be gained in another particle measurement approach. Secondly, ongoing medical research indicates that particle mass may not be the most relevant metric, with various studies instead implicating particle size, number and surface area [ 1 and references contained therein].

Concurrently, concerns over global warming continue to drive the use of biodiesel through the belief that less carbon dioxide is produced on a 'source-to-wheels' basis than with fossil fuels. The biodiesel being used is Fatty Acid Methyl Ester (FAME) and this is blended with mineral-diesel. Incorporating FAME extends the size of the diesel fuel pool in the EU, and reduces reliance on fossil-fuel producing regions. Furthermore, fuel retailers and vehicle operators are free to blend and use FAME at levels above that specified by EN590 $(7 \% \mathrm{v} / \mathrm{v})$ because FAME content is not legally controlled as with 'environmental parameters' such as the amount of Sulphur or Poly-Aromatic Hydrocarbons (PAH) in the fuel.

This situation of increased biodiesel use, with elevated FAME levels, against a background of type approval for particle number, raises some questions for the automotive business. Particle generation in the engine is fundamentally linked to the combustion process of a fuel-air mixture, so it may be surmised that changes in chemical composition of the 
fuel due to FAME blending will affect particle formation and/ or oxidation during the engine operating cycle. Therefore, one might expect differing particle emission levels to be seen when comparing mineral diesel with biodiesel. Many studies in the literature show that FAME has an impact on engine-out particulate mass $[\underline{2}, \underline{3}]$, but there are fewer studies into tailpipe particle number from light-duty applications over the homologation test. Although there is a relationship between particle mass and number, this is dependent on the particle size distribution, so it is important to understand the effects of FAME content on size distribution to quantify the PN-PM relationship and predict any impact on aftertreatment performance.

The particle sizes of interest are in the nano-metre $(\mathrm{nm})$ range, and it is well established in the literature that particles can be separated into three size ranges, known as the nucleation mode, the accumulation mode, and the coarse mode $[\underline{4}, \underline{5}, \underline{6}, \underline{7}]$. The nucleation mode contains the smallest particles $(3 \mathrm{~nm}$ to $50 \mathrm{~nm}[\underline{4}, \underline{5}])$, and is formed mainly through the nucleation of material from the gas-phase during exhaust cooling, although it can also be solid material such as ash. The accumulation mode consists of agglomerated solid particles formed from soot precursors, plus the extraction of material from the gas-phase [1], and has a typical size range of $30 \mathrm{~nm}$ to $500 \mathrm{~nm}[4]$. The coarse mode $(>500 \mathrm{~nm})$ does not come from combustion. The accumulation mode contributes most of the particle mass, and therefore this has been the area receiving the bulk of automotive research. Particle formation and composition is complex, but two key particulate contributors are the carbonaceous fraction and organic fraction. The carbonaceous fraction arises from pyrolysis of fuel in locally fuel-rich areas during combustion, or pyrolysis of oil escaping into the combustion chamber. The organic fraction can come either directly from unburnt fuel/oil, or through incomplete pyrolysis of fuel/oil.

Some previous research has covered the topic on PN emissions from engines operating on biofuel. Zhang et al. [] suggested the total absence of nucleation mode particles with $100 \%$ biodiesel (B100), as well as varying relationships between biodiesel content and the engine operating point, at the sub 400nm size. Li et al. [9] showed lower PN levels with biodiesel in the nano-metre range at two different loads, and that specific reductions compared to mineral diesel are dependant on whether the sample is taken before or after the oxidation catalyst. Some researchers have found that biodiesel increases the number of smaller particles when compared to mineral diesel $[\underline{10}, \underline{11}, \underline{12}, \underline{13}, \underline{14}, \underline{15}, \underline{17}]$. Schönborn et al. conducted tests on a single-cylinder engine operating in the steady-state, and found that biodiesel molecules with longer fatty acid chain lengths tend to produce larger numbers of small particles (5-30nm diameter) than biodiesel molecules with shorter fatty acid chains [17]. Schönborn also found that the degree of saturation of fatty acid alcohol molecules affects particle emissions. Czerwinski et al. [12] showed that the particle size distribution is moved to smaller sizes with both crude rapeseed oil and Rapeseed Methyl Ester (RME), and the nuclei mode is increased. Krahl et al. [13] states that particle numbers below $30 \mathrm{~nm}$ decrease with fossil fuels but exhibit a 10-fold increase with methylester fuels derived from various sources, and Trapel et al. [14] found that with increasing FAME content, the particle size distribution moves towards smaller particles, although the total particle number decreases drastically. There is other evidence of increases in the smaller particles [10], Bertola et al. [11] found a large amount of ultra-fine particles $(<20 \mathrm{~nm})$ in the exhaust during operation with RME, and Krahl et al. [15] showed that RME leads to more particles in the range of $10 \mathrm{~nm}$ to $40 \mathrm{~nm}$ compared to mineral diesel and less particles for the larger diameters.

The variety of results obtained demonstrates the considerable complexity involved when trying to establish the effect of biodiesel on particle number. A significant portion of the studies are on heavy-duty applications or steady-state testing, leaving many questions unanswered for the light duty application over the homologation test, particularly for modern technology such as common rail fuel injection equipment and vehicles fitted with particle aftertreatment. Therefore, the main objective of this work is to quantify any change in total particle number and size distribution due to FAME content, over type-approval emission tests with an engine/vehicle representative of current technology.

\section{TEST FUELS}

The baseline fuel was a mineral diesel meeting the European diesel fuel standard EN 590 and the legislative fuel specification CEC RF-06-03 for European exhaust emissions testing [16]. An analysis of the fuel properties can be found in Table 1, from where it can be seen the baseline fuel did not contain any FAME or ester based additives such as lubricity improvers.

Biodiesel blends were formulated by blending the baseline mineral diesel fuel described above with an EN 14214 compliant FAME, a.k.a. biodiesel fuel. As discussed in the introduction, FAME is a renewable blending component that is widely blended with diesel fuel in many European markets, and in North America. Currently, EN 590 permits a maximum FAME content of $7 \% \mathrm{v} / \mathrm{v}$, although the European Commission has issued a mandate for this to be increased to $10 \% \mathrm{v} / \mathrm{v}$ in the next revision of the standard. As the $7 \%$ limit in EN 590 is not legally binding, fuel retailers are free to operate with blend levels above the limit specified in EN 590, and this is often the case for operators of captive fleets. In North America, the ASTM have released the D7467 standard for diesel fuel containing between 6 and 20\% v/v FAME, and such fuels are becoming widely available. In the experiments described here, FAME was blended volumetrically with the mineral diesel baseline fuel at concentrations of $5 \% \mathrm{v} / \mathrm{v}(\mathrm{B} 5)$, 
Table 1. Properties of mineral diesel and FAME used in this work.

\begin{tabular}{|l|l|l|}
\hline Property (Test method) & Mineral diesel (B0) & FAME (B100) \\
\hline Cetane number (D613) & 53.2 & 52.2 \\
\hline Sulphur content (mg/kg) (IP490) & $<1$ & 1.4 \\
\hline FAME content (\% v/v) (EN14103) & 0 & 98.8 \\
\hline Molar H/C (Calc.) & 1.85 & 1.85 \\
\hline Molar O/C (Calc.) & $<0.0003$ & 0.104 \\
\hline C (\% m/m) (D5921) & 86.62 & 77.24 \\
\hline H (\% m/m) (D5921) & 13.38 & 11.94 \\
\hline O (\% m/m) (Elemental Analysis) & $<0.04$ & 10.7 \\
\hline H/C (Calc.) & 0.1545 & 0.1546 \\
\hline Net calorific value (MJ/kg) (IP12) & 43.00 & 37.39 \\
\hline Methanol content (\% v/v) (EN14110) & - & 0.04 \\
\hline Mono-glyceride (\% m/m) (EN14105) & - & 0.43 \\
\hline Di-glyceride (\% m/m) (EN14105) & - & 0.09 \\
\hline Tri-glyceride (\% m/m) (EN14105) & - & \\
\hline Total glycerol (\% m/m) (EN14105) & - & \\
\hline Free glycerol (\% m/m) & - & \\
\hline
\end{tabular}

$10 \% \mathrm{v} / \mathrm{v}(\mathrm{B} 10)$ and $30 \% \mathrm{v} / \mathrm{v}(\mathrm{B} 30)$. Blend levels were verified by an in-house gas chromatogram procedure [18]. This test reported FAME concentrations of $4.27 \% \mathrm{v} / \mathrm{v}$ for the $\mathrm{B} 5,10.24 \% \mathrm{v} / \mathrm{v}$ for the $\mathrm{B} 10$ and $31.16 \% \mathrm{v} / \mathrm{v}$ for the B30.

$<\underline{\text { table } 1}$ here $>$

Table 1 shows that the FAME contains $10.7 \% \mathrm{~m} / \mathrm{m}$ oxygen. This oxygen arises due to the two oxygen atoms contained in the ester functional group. Although not clearly elucidated by the data in the table, a significant fraction of the (aliphatic) side-chains in the FAME molecules are likely to be mono- or even poly-unsaturated.

The physical effects of FAME blending on the finished fuel were quantified by measurement of the ASTM D86 distillation curves and D445 viscosity at $40^{\circ} \mathrm{C}$. These data are presented in the results section together with a discussion of the aromatics level in the finished test fuels.

The presence of the ester group, and associated physical effects described above are expected to influence the engine emissions performance. Sulphur was not considered in detail because both the baseline mineral diesel and the FAME contained only $\sim 1 \mathrm{mg} / \mathrm{kg}$ Sulphur or less.

\section{TEST METHODOLOGY EQUIPMENT}

Testing was conducted at the Ford Dunton Technical Centre in the UK in a test cell conforming to ECE Regulation No. 83 [19] and approved by the UK Department of Transport 
Vehicle Certification Agency and German Technical Inspection Association. The equipment included a CVS/ Dilution Tunnel system, particulate sampling onto filters (Pallflex TX40), gaseous analysers, and chassis dynamometer. Additional equipment used included a Cambustion Differential Mobility Spectrometer (DMS500), Horiba Solid Particle Counting System (SPCS), AVL PhotoAcoustic Soot Sensor (Model 483), and Perkin-Elmer GasChromatograph (GC). Test variability was minimized through the use of a robot driver, plus rapid vehicle cooling between tests which promotes test stability by allowing the vehicle to remain in position on the dynamometer during repeat testing on each fuel. The test vehicle was a CD-class model with a Euro4 compliant 2000cc high-pressure common-rail diesel engine. Data from the Powertrain Control Module (PCM) were collected for every test.

\section{METHOD}

The four fuels were tested using standard emission tests from European and Federal (USA) legislation. The European tests are of main interest here, but the Federal tests consist of more transient driving patterns potentially providing different results. Each fuel was tested with five NEDC cycles [20] and two FTP75 cycles [21]. Each test was conducted from ambient temperature at 20-30degC (colloquially a 'cold test') after a rapid vehicle cool down with chilled engine coolant and multiple high-speed cooling fans. Before changing fuel, all data were checked for quality and consistency. At the start, and after each fuel change, two conditioning drives were carried out, each consisting of three NEDC Part Two cycles (Extra-Urban). For all this work the DPF was removed from the vehicle to gain insights into particle emissions from the engine and into the DPF. The vehicle PCM was flashed with a non-DPF version of the production calibration. Realtime data were collected at $10 \mathrm{~Hz}$ and post-processed to obtain results at the vehicle tailpipe normalised by distance, as required for reporting regulated emission results. During particle sampling, the DMS was set to a 4:1 dilution which was found suitable to prevent saturation of the DMS electrometers. Furthermore, the DMS sample was taken from the dilution tunnel which was set at a CVS flowrate of 600 cubic feet per minute. The dilution-corrected concentration from the DMS was then used in conjunction with CVS volume to determine tailpipe PN emissions.

\section{RESULTS AND DISCUSSION}

\section{FUEL}

Figure 1 shows the effect of FAME blending on the volatility of the finished fuel. The boiling range of the FAME molecules lies within the normal diesel hydrocarbon boiling range, and so the initial and final boiling points of the fuel are unaffected. Whilst the sigmoidal shape is retained, the FAME does cause a reduction in the mid-range volatility. This can be quantified by comparison of the T50 for the $\mathrm{B} 30\left(298^{\circ} \mathrm{C}\right)$ and the T50 for the mineral diesel baseline $\left(271^{\circ} \mathrm{C}\right)$, which is $27^{\circ} \mathrm{C}$ lower.

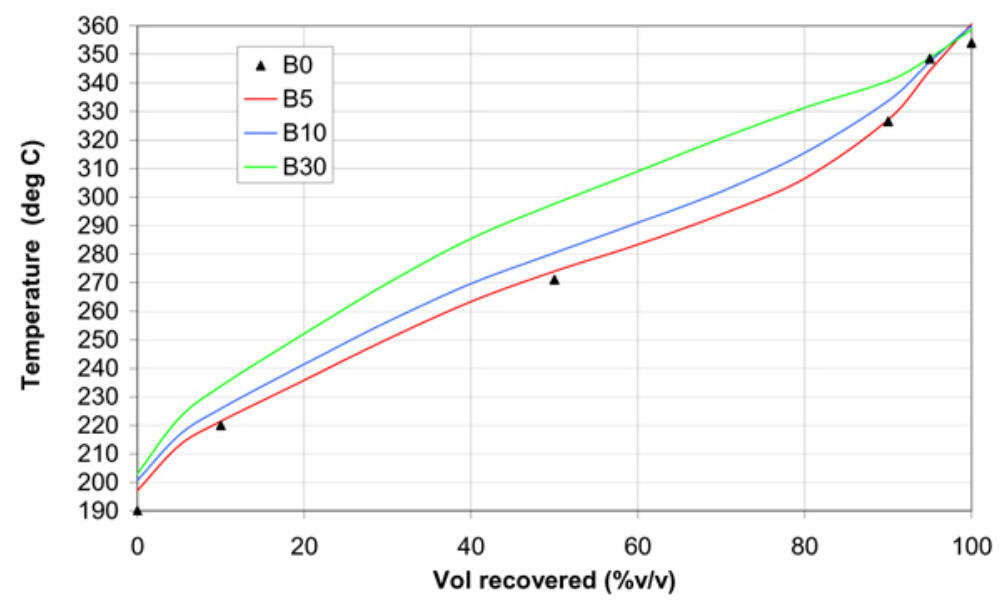

Figure 1. ASTM D86 distillation curves for the test fuels.

Figure 2 shows the effect of FAME blending on the kinematic viscosity of the finished fuel at $40^{\circ} \mathrm{C}$. Consistent with the shift in distillation curve, the introduction of $30 \% \mathrm{v} /$ v FAME increases this viscosity from $2.5 \mathrm{cSt}$ in the base fuel to $3.05 \mathrm{cSt}$.

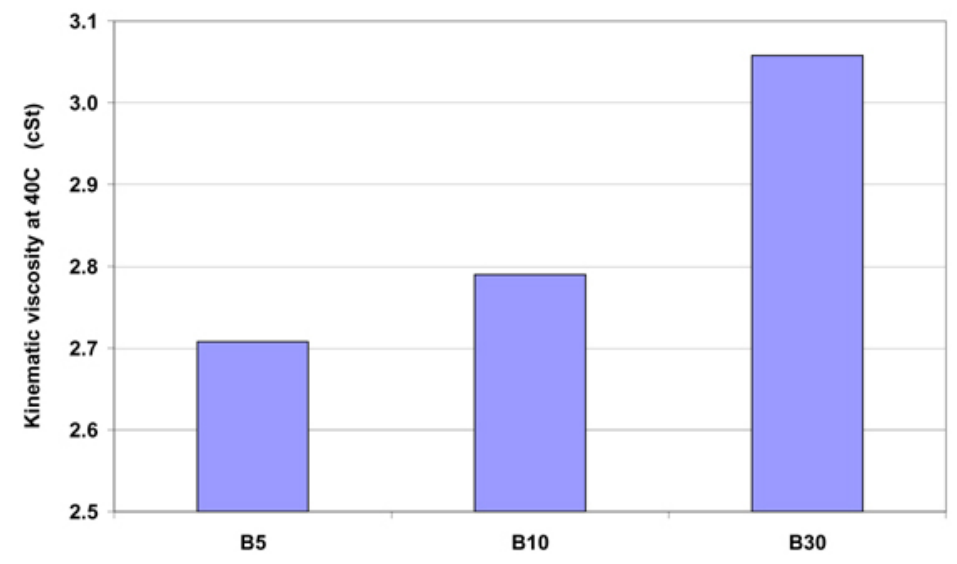

Figure 2. Kinematic viscosity at $40^{\circ} \mathrm{C}$ for the $\mathrm{B5}, \mathrm{B} 10$ and B30 fuels, measured according to IP71/97.

In addition to the effect on the volatility (Figure 1) and viscosity (Figure 2), some authors report that FAME has a higher bulk modulus of compressibility than mineral diesel [22]. In applications with pump-line-nozzle fuel injection equipment, the timing of the fuel injection event depends on the speed of sound in the fuel, which increases in proportion to the bulk modulus. In the experiments described here, a common-rail fuel injection equipment architecture was used. The injection timing in these systems may be considered independent of the compressibility of the fuel, and so changes in injection timing due to FAME content were not considered further. Similarly, a reduction in ignition delay has been 
proposed as a partial explanation for increases in $\mathrm{NO}_{\mathrm{x}}$ emissions. Inspection of Table 1 shows that the FAME and mineral diesel fuels used here have cetane numbers of 53.2 and 52.2 respectively. Assuming linear blending behavior, this difference is small enough to neglect. It can therefore be inferred that any advancing of the combustion timing due to either injection timing advance and/or a shortening of the ignition delay period are not likely to be major contributory factors in any changes to the emissions performance in the experiments described here.

The oxygen content in the finished test fuels may be calculated by assuming a linear blending relationship. This yields values of $0.5 \% \mathrm{~m} / \mathrm{m}, 1 \% \mathrm{~m} / \mathrm{m}$ and $3 \% \mathrm{~m} / \mathrm{m}$ oxygen for the B5, B10 and B30 fuels respectively. The decrease in volumetric energy density of the test fuels vs the mineral diesel baseline is expected to vary as the inverse of these values. A small $(<0.5 \% \mathrm{v} / \mathrm{v})$ concentration of high molecular weight compounds such as tri-glycerides are also carried by the FAME into the test fuels. Their presence is noted due to their molecular weight $\left(\sim \mathrm{C}_{55}\right.$ for tri-glyceride), which is significantly higher than normal diesel hydrocarbons.

In addition to the introduction of oxygen and glycerides, the composition of the finished fuel is altered by the dilution of compounds in the mineral diesel baseline that are not present in the FAME. The concentration of aromatics and poly-cyclic aromatics are of interest due to their effectiveness at forming carbonaceous particulate matter. A finished test fuel containing $\mathrm{X}_{\mathrm{FAME}} \mathrm{v} / \mathrm{v}$ will have an aromatics content equal to a factor of $\left(1-\mathrm{X}_{\mathrm{FAME}}\right)$ of that in the baseline mineral diesel. For example, the concentration of aromatics in the $\mathrm{B} 30$ is $20.1 \% \mathrm{v} / \mathrm{v}$ compared to $28.7 \% \mathrm{v} / \mathrm{v}$ in the mineral diesel.

\section{PARTICLE NUMBER/SIZE}

A number of relationships were found between PN emissions and FAME content. Figure 3,Figure 4,Figure 5, Figure 6,Figure 7 in this section contain averaged results from each set of testing on each fuel. The two columns shown for each fuel blend relate to results from the entire NEDC or FTP test cycle. The labels on the $\mathrm{x}$-axis in each graph represent the nominal FAME content of each fuel. Sampling was taken from the dilution tunnel with the DPF removed. Statistical analysis (t-test) showed high confidence that total PN results from each fuel were not from the same population (i.e. the means are genuinely different after accounting for result variation). Error bars represent two standard deviations. The majority of results were obtained with the Cambustion DMS500, with some further results obtained using a Euro5compliant particle counting system (Horiba SPCS).

Figure 3 shows that 'total' PN (defined as nucleation mode plus accumulation mode) decreases as FAME content is increased. Figure 4 shows the total PN results as a percentage of the B0 baseline (note that the baseline level is different for each test cycle as shown in Figure 3). For the NEDC, total PN drops from the B0 level by $4.3 \%, 5.4 \%$, and $16 \%$ for B5, $\mathrm{B} 10$ and $\mathrm{B} 30$ respectively, and by $2.1 \%, 12.3 \%$, and $23 \%$ for the FTP. Table 2 shows the percentage change from B0 for the individual parts of each test cycle.

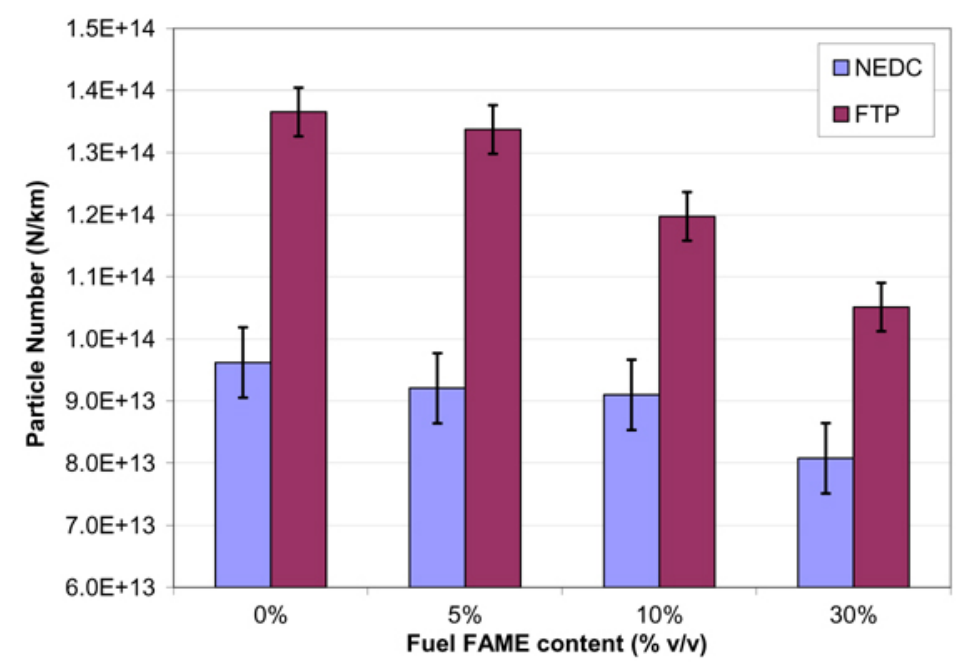

Figure 3. Total particle number emissions (by DMS) over NEDC \& FTP cycles versus FAME content in the fuel; total length of error bars is two standard deviations.

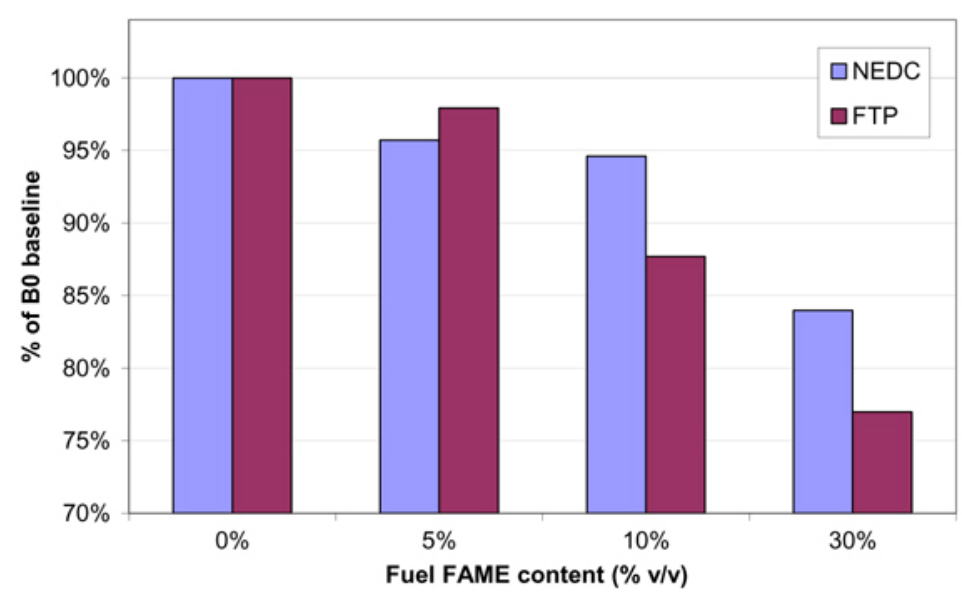

Figure 4. Total PN as percentage of BO baseline for each test type. Note: the baseline values are different for each test type (see Figure 3).

$<$ table 2 here $>$

The PN data can be further analysed by looking at individual totals for the accumulation and nucleation modes. Figure 5 shows that accumulation mode $\mathrm{PN}$, which represents predominantly carbonaceous particles, also shows a clear downward trend with increasing FAME content. Approximately $75-85 \%$ of the total PN (nuc+acc mode) is from the accumulation mode. Figure 6 shows an increase in 
Table 2. change in Total PN for each part of the test cycle (NEDC \& FTP) from BO baseline values.

\begin{tabular}{|l|l|l|l|}
\hline & \multicolumn{3}{|l|}{ Change in Total PN from B0 Baseline } \\
\hline Cycle & B5 & B10 & B30 \\
\hline NEDC Part One (0-780secs) & $-6.9 \%$ & $-3.4 \%$ & $-8.0 \%$ \\
\hline NEDC Part Two (780-1180secs) & $-1.2 \%$ & $-8.1 \%$ & $-25.8 \%$ \\
\hline FTP Part One (0-505secs) & $-7.0 \%$ & $-13.0 \%$ & $-21.5 \%$ \\
\hline FTP Part Two (505-1374secs) & $0.0 \%$ & $-7.2 \%$ & $-14.9 \%$ \\
\hline FTP Part Three (1374-1879secs) & $-4.5 \%$ & $-11.3 \%$ & $-31.1 \%$ \\
\hline
\end{tabular}

nucleation mode with increasing FAME content. From B0 to $\mathrm{B} 30$, a rise of $25.1 \%$ and $26.3 \%$ is seen for the NEDC and FTP respectively.

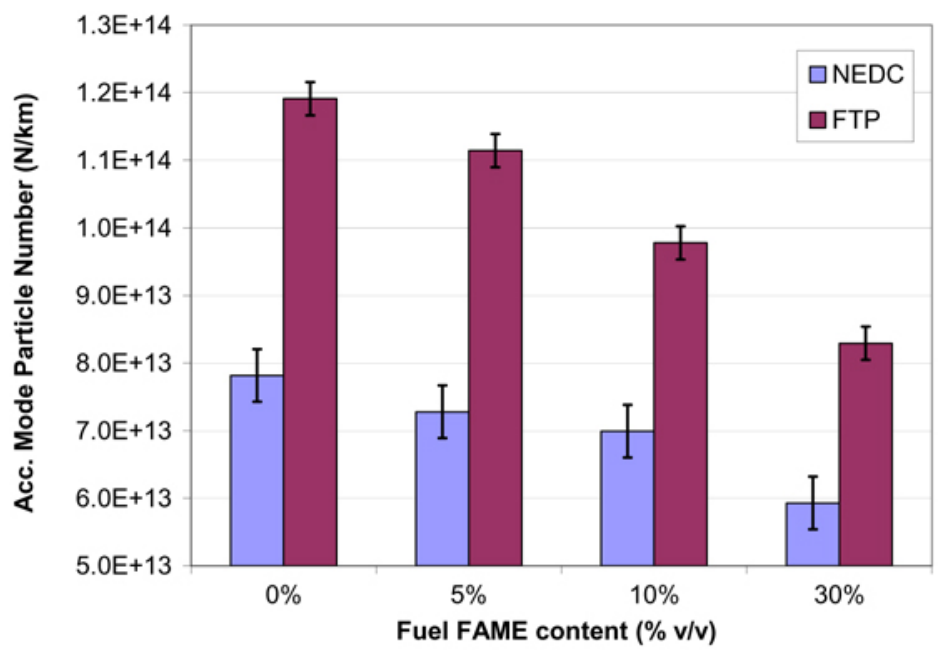

Figure 5. Accumulation mode particle emissions (by $D M S)$ over NEDC \& FTP cycles versus FAME content in the fuel; total length of error bars is two standard deviations.

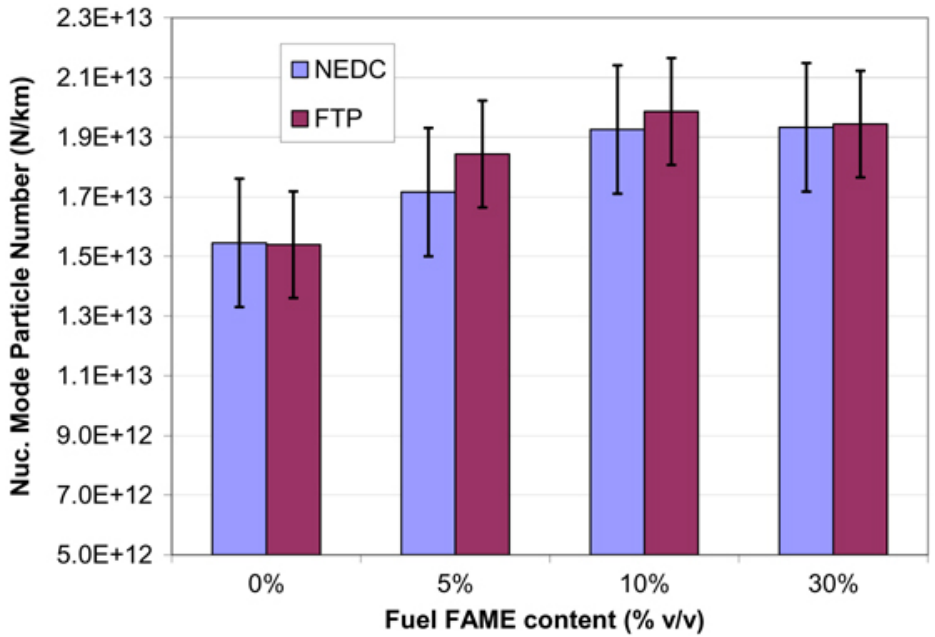

Figure 6. Nucleation mode particle emissions (by DMS) over NEDC \& FTP cycles versus FAME content in the fuel; total length of error bars is two standard deviations.

It therefore follows that the ratio between nucleation and accumulation changes with FAME content. Over the NEDC, nucleation mode contributes $\approx 16 \%$ to total $\mathrm{PN}$ with $\mathrm{B} 0$, increasing to $\approx 24 \%$ with B30. The FTP shows nucleation mode increasing from $\approx 11 \%$ of total $\mathrm{PN}$ with $\mathrm{B} 0$ to $\approx 18 \%$ with B30. In other words, more small volatile particles exist in exhaust from FAME-containing fuel than with mineralderived diesel. The fuel distillation curves show the FAME blends have a higher mean molecular weight than mineral diesel (evident from Figure 1), so any unburnt fuel is more likely to condense as the exhaust cools. Also, the reduction in accumulation mode provides less surface area for volatile material to be adsorbed leaving volatile material free to form nucleation mode particles. The accumulation mode reduction is probably due to a) the effect of FAME-bound oxygen on the rates of pyrolytic and oxidation reactions in fuel rich zones within the combustion chamber, resulting in less soot 
leaving the cylinder [17] and b) a reduction in fuel aromatics with FAME content. These findings also suggest the composition of particulate (volatile/carbonaceous ratio) differs depending on the level of FAME, which may have implications for regeneration of particle aftertreatment. Papers by Boehman, Song and Zabetta $[\underline{23}, \underline{24}, \underline{25}]$ suggest that this is in fact the case. Although it was not investigated here, the same authors report an increase in the soot reactivity and a more amorphous (less graphitic) soot micro-structure for soot derived from fuel containing FAME. It is interesting to note the experimental precision is in a similar range for both modes, although the nucleation mode exhibits higher variance as a percentage of the mean. Nucleation particles are thought to be more difficult to measure accurately and more susceptible to sampling methods.

The nucleation mode increase, coupled with an accumulation mode decrease, suggests that the mean size of particle from FAME-containing fuel should be less than mineral-derived diesel. Figure 7 shows the geometric mean diameter for each fuel, with a drop of $\approx 11 \mathrm{~nm}(\approx 18 \%)$ in the mean particle size between $\mathrm{B} 0$ and $\mathrm{B} 30$ for the NEDC, and $\approx 21 \mathrm{~nm}(\approx 28 \%)$ for the FTP. It is also clear that the geometric mean particle size is larger for the more transient FTP cycle.

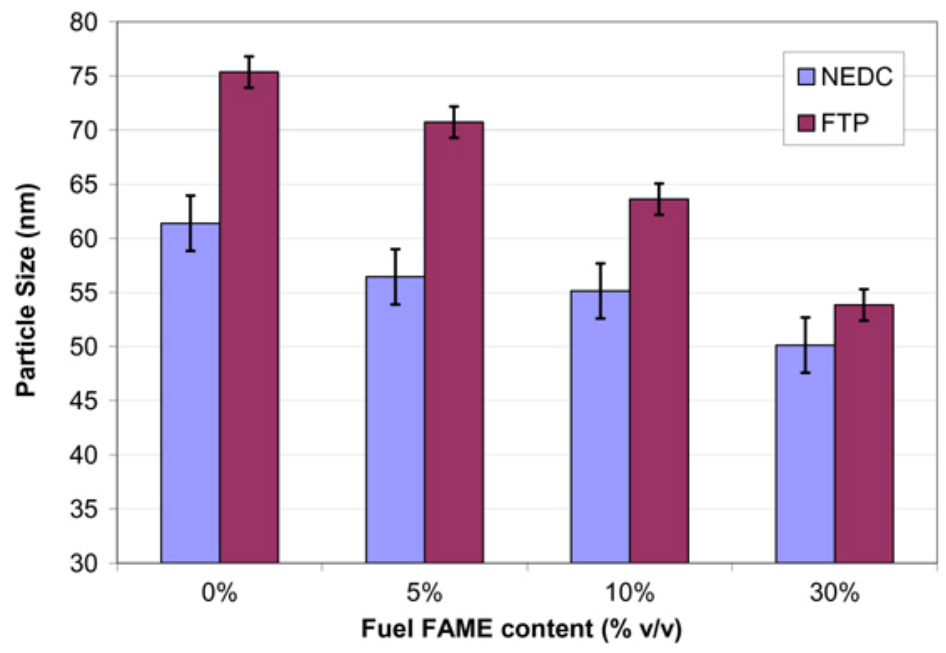

Figure 7. Geometric mean particle size (by DMS) over NEDC \& FTP cycles versus FAME content in the fuel; total length of error bars is two standard deviations.

To review particle size in more detail, the size distribution can be plotted. Figure 8 shows the particle size distribution averaged in time (entire NEDC) and over all tests for each fuel. The expected bimodal distribution is present, with the nucleation mode ending at about $50 \mathrm{~nm}$. The nucleation peak is highest with B30 fuel and moves progressively lower as FAME content is decreased. The opposite is true of the accumulation mode peak. This agrees with data in Figure 5 and Figure 6 and the associated discussion. Smaller particles contribute less to overall mass, and the Euro5 compliant PN measurement system has some particle size discrimination (a $23 \mathrm{~nm}$ lower size cut), so understanding any changes in particle size/number/mass relationship due to fuel composition is particularly important.

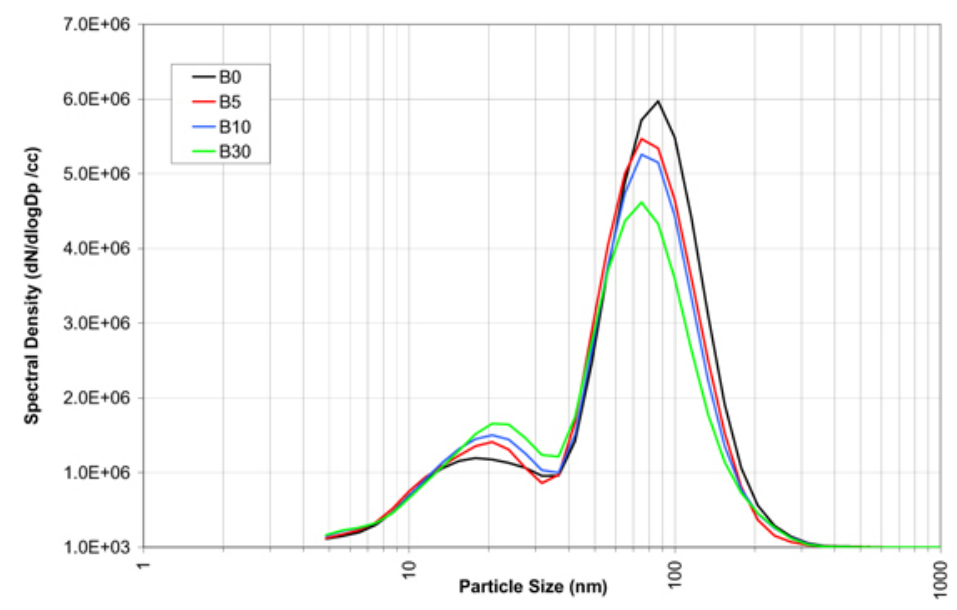

Figure 8. Particle size distribution (DMS) over NEDC cycle for different FAME contents.

To investigate exactly where the differences in PN emissions occur within the cycle, the real-time data can be reviewed. Figure 9 and Figure 10 show traces of real-time total PN data which are representative of the average over multiple tests for each fuel. Significant differences can clearly be seen during accelerations and cruises, particularly during Part Two of the NEDC which contains a higher speed/load operating region where accumulation mode particles dominate. Figure 11 shows the cumulative PN emissions for each fuel over individual representative tests.

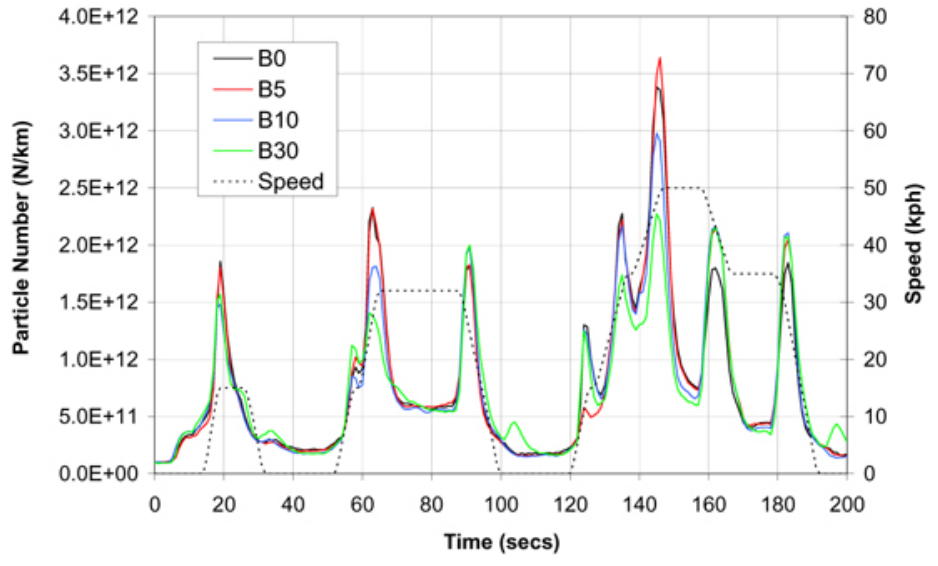

Figure 9. real-time total particle emissions (DMS) over NEDC cycle one for different FAME contents. 


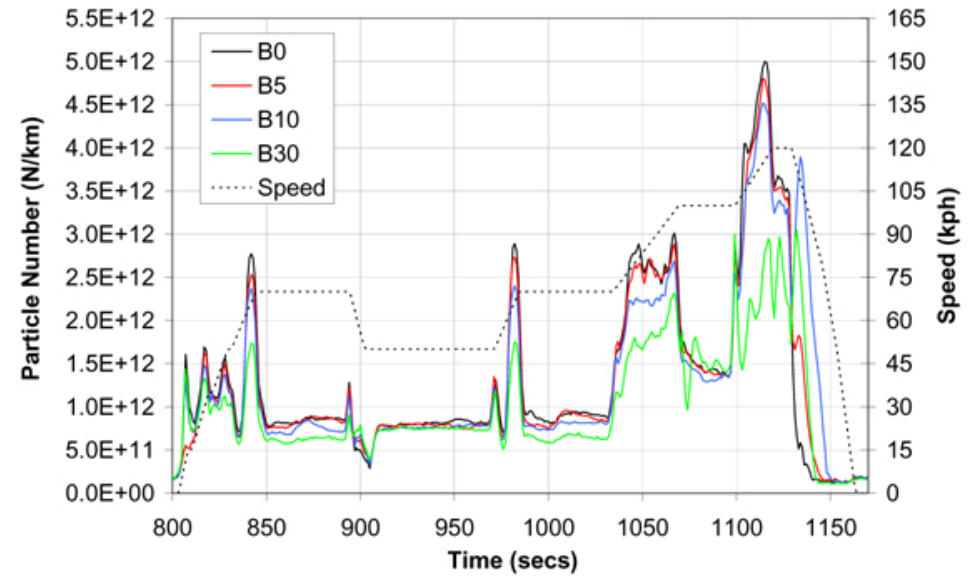

Figure 10. real-time total particle emissions (DMS) over NEDC part two for different FAME contents.

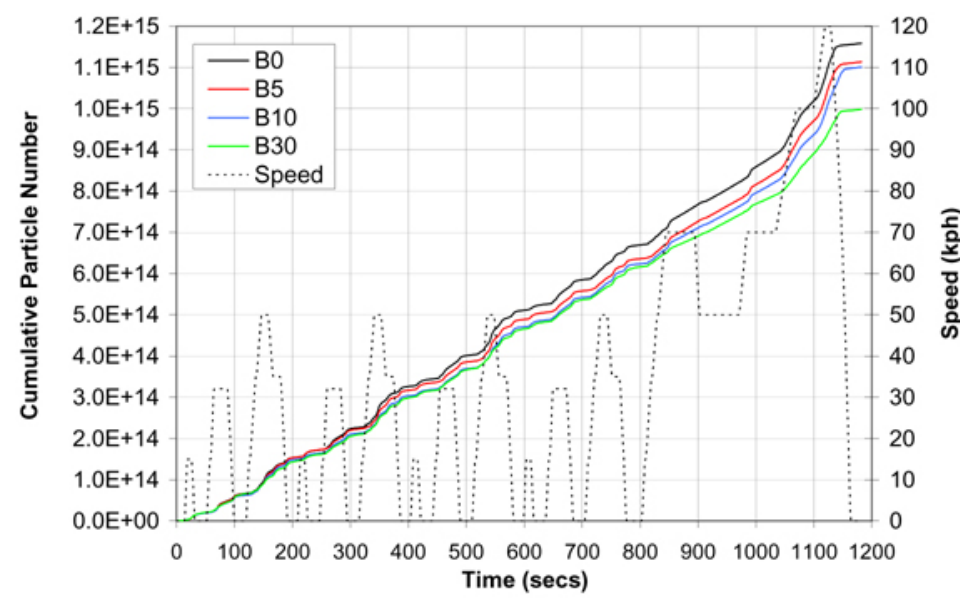

Figure 11. cumulative total particle emissions (DMS) over representative $N E D C$ cycles for different $F A M E$ contents.

Figure 12 shows results from a Euro5-compliant PN measurement system (SPCS) and DMS, obtained from a further set of testing in a different test cell. It can be seen that the trend of lower PN with increased FAME is confirmed with a different measurement technique, and that the SPCS gives lower PN than by DMS (nuc+acc). This is due in part to the Volatile Particle Remover present in the SPCS, and the different particle size range, particle detection, counting principles, and calibration methodologies of the two instruments.

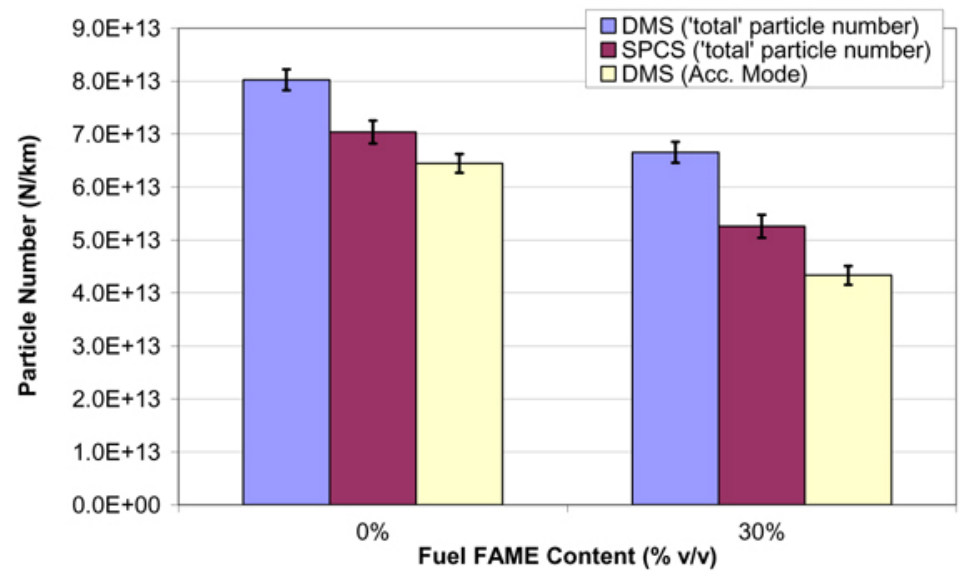

Figure 12. particle number measured by DMS and SPCS for BO and B30 fuels over NEDC total test; total length of error bars is two standard deviations.

\section{PARTICULATE/SOOT MASS}

As might be expected from the particle number findings, particulate mass (PM) and soot mass were also found to reduce with increasing FAME content. Figure 13 shows PM emissions $(\mathrm{g} / \mathrm{km})$ from the filter method for the whole NEDC and FTP tests. $\mathrm{A} \approx 30 \%$ reduction in PM is seen between $\mathrm{B} 0$ and B30. Figure 14 contains the cumulative soot mass measured by the Photo-Acoustic Soot Sensor over FTP part one, with $\mathrm{B} 30$ showing a $\approx 35 \%$ drop from $\mathrm{B} 0$. As noted for the accumulation mode reduction, this may be explained by the effect of fuel-bound oxygen on the balance between oxidation and pyrolytic reactions within the cylinder, and the lower fuel aromatics content.

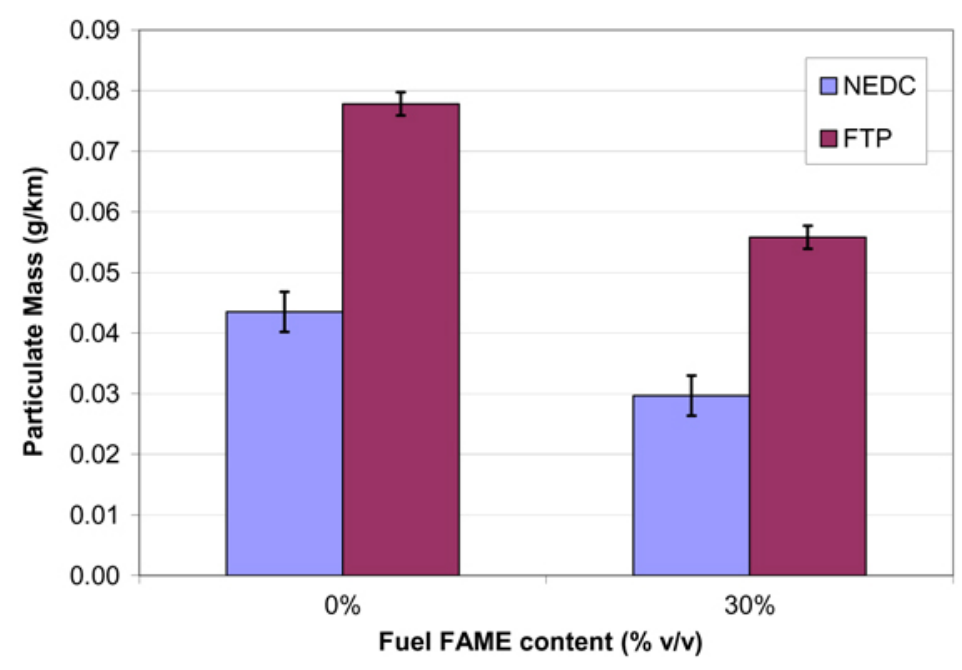

Figure 13. total particulate mass emissions over NEDC \& FTP cycles versus FAME content in the fuel; total length of error bars is two standard deviations. 


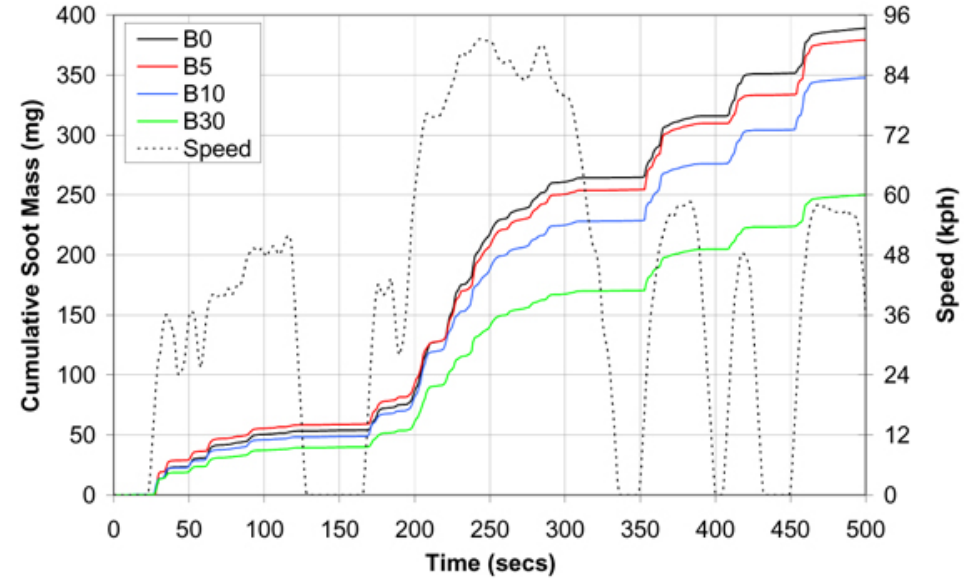

Figure 14. cumulative soot emissions over the FTP part one cycle for different FAME contents.

Further evidence of reduced PM/Soot mass can be found through examining the state of the DPF at various points during repeated drive cycles. The DPF was refitted to the vehicle and a series of repeat cycles driven whilst monitoring the pressure-drop across the DPF. The pressure drop indicates the soot load on the DPF, and is a key part of the DPF management strategy to determine when regeneration is needed. Figure 15 shows the pressure-drop data plotted against the distance driven, for both $\mathrm{B} 0$ and $\mathrm{B} 30$ fuel. The B30 data shows that filter loading is achieved more slowly (by approximately $40 \%$ ) using B30 fuel, which is consistent with the decreased levels of engine-out particle number and mass found. Differences in DPF loading time/distance between different fuels could have implications for accurate scheduling of DPF regenerations.

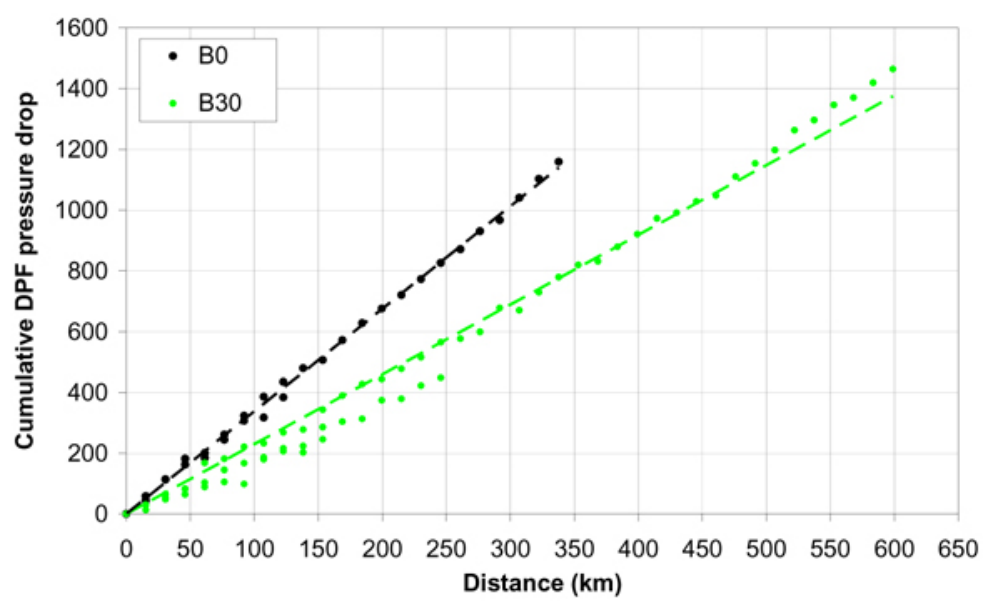

Figure 15. DPF pressure drop normalised by volume flowrate through DPF (idle condition) v. distance driven for two different fuels, BO v. B30

\section{FILTER SPECIATION/PARTICULATE COMPOSITION}

As well as the total particulate mass, further analysis of the particulate filter papers was carried out via thermo-desorption and gas chromatography. No significant correlations with FAME content were found for the lighter organic fraction, sulphates (due to negligible fuel sulphur level) and nitrate fractions. However, FAME peaks were found in the analysis of particulate matter, suggesting that unburnt FAME carries through to the tailpipe particulate. Also, an increase in high molecular-weight organic compounds was observed. The elution time for these compounds was within the range of crankcase lubricating oil. However, it is conceivable that some of these unresolved high molecular weight compounds may derive from the glycerides mentioned previously. Although their concentration in the fuel was low $(\sim 0.3 \% \mathrm{~m} /$ $\mathrm{m}$ in the B30), their high molecular weight suggests that they are likely to become super-saturated on exhaust cooling, and therefore likely to add to the organic mass in the particulate phase. It is interesting to note that some authors implicate these compounds (glycerides and sterols) as being responsible for filter plugging at low temperatures. The suggestion is that they may precipitate out of the liquid phase at temperatures above the cloud point - i.e. above that expected for normal diesel hydrocarbons.

\section{GASEOUS EMISSIONS}

A review of the gaseous emissions results shows that a significant impact was found for nitrogen oxides $\left(\mathrm{NO}_{\mathrm{x}}\right)$ as shown in Figure 16. This was expected and has been previously reported in the literature $[12,13]$. Increases of 6 to $7 \%$ were seen over the NEDC and FTP cycles, for B30 versus B0. This compares to a $9-25 \%$ increase seen with an EU3 engine with pump-line-nozzle fuel injection equipment [13]. Several possible explanations exist for the biodiesel $\mathrm{NO}_{\mathrm{x}}$ effect. In these experiments, isentropic compressibility effects are discounted on the basis of the common rail fuel injection equipment used, and changes in ignition delay are discounted on the basis of the similarity of the cetane numbers. Although a quantitative deconvolution of the factors affecting $\mathrm{NO}_{\mathrm{x}}$ emissions is beyond the present scope, the most likely explanations are that the amount of NO produced via the Zeldovich mechanism is increased due to an increase in the adiabatic flame temperature [27] in proportion to the FAME content, and/or that the amount of $\mathrm{NO}$ formed via the Fenimore mechanism [26] is increased [17]. 


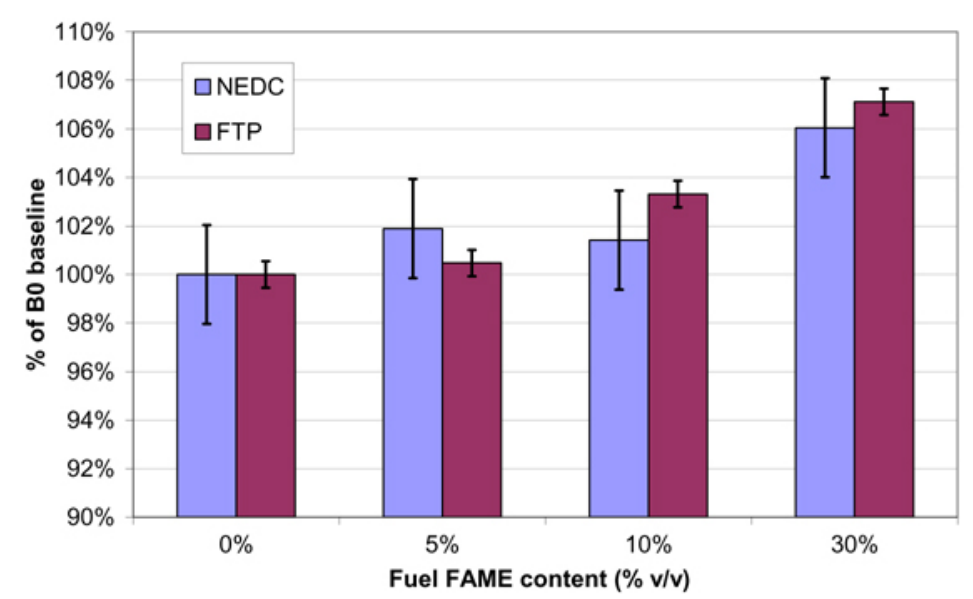

Figure 16. Percentage change in total $\mathrm{NO}_{x}$ emissions from the BO baseline values for each test type. Note: the BO baseline values are different for each test type $(0.23 \mathrm{~g} /$ $\mathrm{km}$ for the $\mathrm{NEDC}$, and $0.39 \mathrm{~g} / \mathrm{km}$ for the FTP); total length of error bars is two standard deviations.

\section{SUMMARY/CONCLUSIONS}

Work was carried out in order to study the effect of FAME blending on the fuel itself and the resulting particle number, size, and mass emissions when used in a Euro4 compliant high-pressure common rail diesel engine fitted to a modern passenger vehicle. The test fuels were analysed to ensure a good understanding of the experimental inputs, and testing was conducted in a test cell suitable for type-approval emission testing over the homologation drive cycles for Europe and the US. The bulk of particle number measurements were achieved with a Cambustion DMS500, and then key results verified using a particle number measurement system compliant with the Euro5 amendments to ECE Regulation 83. The conclusions from this investigation are as follows:-

FAME blending has the following effects on the fuel:-

- Physical effects include a reduction in mid-range volatility and an increase in the kinematic viscosity of the test fuels. FAME bound oxygen and a small amount of high molecular weight organic compounds (glycerides) are introduced to the test fuels on FAME blending. FAME also acts as a diluent, reducing the concentration of aromatic compounds in the finished test fuels. The effect of these changes on exhaust emissions are as follows (\% change from B0 to B30 over NEDC shown in brackets):-

- A decrease in total Particle Number (-16\%), accumulation mode PN (-24\%), geometric mean particle size $(-18 \%)$, particulate mass $(-32 \%)$, and soot mass emissions $(-34 \%)$. Although total particle number was found to decrease, an increase in the number of nucleation mode particles was observed $(+25 \%)$.
- Analysis of the PM composition showed a decrease in the mass of the carbon fraction and an increase in the fraction of high molecular weight organic compounds. FAME was observed in this fraction, as were heavier compounds which may derive from FAME borne glycerides.

- The changes in particle number, size and composition mentioned above are relevant to applications with diesel particulate filters. The number, mass and size reduction (with FAME blends) were shown to cause a reduction in DPF loading time for B30 vs B0.

- An increase in $\mathrm{NO}_{\mathrm{x}}$ emissions of 6 - 7\% for B30 vs B0 was observed for the common rail fuel injection engine tested here. The increase was smaller than that reported in the literature for engines with pump-line-nozzle fuel injection equipment.

\section{REFERENCES}

1. Eastwood, P., "Particulate Emissions from Vehicles", SAE International, Wiley Publishing, ISBN 978-0-7680-2060-1, 2008.

2. Lapuerta, M., Armas, O., Ballesteros, R., and Carmona, M., "Fuel Formulation Effects on Passenger Car Diesel Engine Particulate Emissions and Composition," SAE Technical Paper 2000-01-1850, 2000.

3. Wu, F., Wang, J., Chen, W., and Shuai, S., "Effects of Different Biodiesels and their Blends with Oxygenated Additives on Emissions from a Diesel Engine," SAE Technical Paper 2008-01-1812, 2008.

4. Kittleson, D., "Physics of solid particles emitted by ICengines, Course on Ultrafine Diesel Particles and Retrofit technologies for Diesel Engines", Nov 12-2008.

5. Schaberg, P., Zarling, D., Waytulonis, R., and Kittelson, D., "Exhaust Particle Number and Size Distributions with Conventional and Fischer-Tropsch Diesel Fuels," SAE Technical Paper 2002-01-2727, 2002.

6. Hall, D., Stradling, R., Zemroch, P., Rickeard, D., Mann, N., Heinze, P., Martini, G., Hagemann, R., Rantanen, L., and Szendefi, J., "Measurement of the Number and Size Distribution of Particle Emissions from Heavy Duty Engines," SAE Technical Paper 2000-01-2000, 2000.

7. Thompson, N., Ntziachristos, L., Samaras, Z., Aakko, P., Wass, U., Hausberger, S., and Sams, T., "Overview of the European Particulates Project on the Characterization of Exhaust Particulate Emissions from Road Vehicles: Results for Heavy Duty Engines," SAE Technical Paper 2004-01-1986, 2004.

8. Zhang, X., Wang, H., Li, L., Wu, Z., Hu, Z., Zhao, H., and Yang, W., "Characteristics of Particulates and Exhaust Gases Emissions of DI Diesel Engine Employing Common Rail Fuel System Fueled with Bio-diesel Blends," SAE Technical Paper 2008-01-1834, 2008. 
9. Li, H., Lea-Langton, A., Andrews, G., Thompson, M., and Musungo, C., "Comparison of Exhaust Emissions and Particulate Size Distribution for Diesel, Biodiesel and Cooking Oil from a Heavy Duty DI Diesel Engine," SAE Technical Paper 2008-01-0076, 2008.

10. Aakko, P., and Nylund, N., "Particle Emissions at Moderate and Cold Temperatures Using Different Fuels," SAE Technical Paper 2003-01-3285, 2003.

11. Bertola, A., Schubiger, R., Kasper, A., Matter, U., Forss, A., Mohr, M., Boulouchos, K., and Lutz, T., "Characterization of Diesel Particulate Emissions in HeavyDuty DI-Diesel Engines with Common Rail Fuel Injection Influence of Injection Parameters and Fuel Composition," SAE Technical Paper 2001-01-3573, 2001.

12. Czerwinski, J., Zimmerli, Y., Neubert, T., Heitzer, A., and Kasper, M., "Injection, Combustion and (Nano) Particle Emissions of a Modern HD-Diesel Engine with GTL, RME \& ROR," JSAE 20077072, SAE Technical Paper 2007-01-2015, 2007.

13. Krahl, J., Munack, A., Schröder, O., Stein, H., Herbst, L., Kaufmann, A., and Bünger, J., "The Influence of Fuel Design on the Exhaust Gas Emissions and Health Effects," SAE Technical Paper 2005-01-3772, 2005.

14. Trapel, E., Mayer, C., Schulz, C., and Roth, P., "Effects of Bio Diesel Injection in a DI Diesel Engine on Gaseous and Particulate Emission," SAE Technical Paper 2005-01-2204, 2005.

15. Krahl, J., Munack, A., Schröder, O., Stein, H., and Bünger, J., "Influence of Biodiesel and Different Designed Diesel Fuels on the Exhaust Gas Emissions and Health Effects," SAE Technical Paper 2003-01-3199, 2003.

16. EC Regulations $715 / 2007$ and amending regulation $692 / 2008$.

17. Schönborn, A., Ladommatos, N., Allan, R., Williams, J., and Rogerson, J., "Effect of the Molecular Structure of Individual Fatty Acid Alcohol Esters (Biodiesel) on the Formation of $\mathrm{NO}_{\mathrm{x}}$ and Particulate Matter in the Diesel Combustion Process," SAE Int. J. of Fuels and Lubricants 1(1):849-872, 2008.

18. Gould, S., Ford Motor Company Limited, personal communication, Feb. 2009.

19. "Uniform Provisions Concerning The Approval Of Vehicles With Regard To The Emission Of Pollutants According To Engine Fuel Requirements" - ECE Regulation No. 83. Available from http://www.unece.org/trans/main/ wp29/wp29regs81-100.html.

20. "Breakdown Of The Operating Cycle Used For The Type I Test" - ECE Regulation No. 83, Annex 4, Appendix 1. Available from http://www.unece.org/trans/main/wp29/ wp29regs81-100.html.

21. Title 40 "Protection of Environment", Part 86 -"Control Of Emissions From New And In-Use Highway Vehicles And
Engines", Appendix I - Urban Dynamometer Schedules. Available from http://www.gpoaccess.gov/cfr/retrieve.html.

22. Boehman, A., Morris, D., Szybist, J., and Esen, E., "The impact of the bulk modulus of diesel fuels on fuel injection timing", Energy \& Fuels(18):1877-1882, 2004.

23. Boehman, A., Song, J., and Alam, M., "Impact of Biodiesel Blending on Diesel Soot and the Regeneration of Particulate Filters" Energy \& Fuels, Vol. 19, No. 5:1857-1864, 2005.

24. Song, J., Alam, M., Boehman, A., and Kim, U., "Examination of the oxidation behavior of biodiesel soot", Combustion and Flame 146:589-604, 2006.

25. Zabetta, E., Hupa, M., and Niemi, S., "Bio-derived fuels may ease the regeneration of diesel particulate traps", Fuel 85:2666-2670, 2006.

26. Fenimore, C., Proc. Combust. Inst. 13:373, 1971.

27. Ban-Weiss, A., Chen, J., Buchholz, B., and Dibble, R., "A numerical investigation into the anomalous slight NOx increase when burning biodiesel; A new (old) theory", Fuel Processing Technology 88, 659-667, 2007.

\section{CONTACT INFORMATION}

Mark Tinsdale

15/1L-C06-B

Ford Motor Company

Dunton Technical Centre

Essex, SS15 6EE, England

mtinsdal@ford.com

\section{ACKNOWLEDGMENTS}

The authors would like to acknowledge the contribution from the following colleagues to the experimental work:- Marc Ealy, Phil Rowland, Mark Sayers, Ian Emery, Stephen Gould and Keith Sturgeon.

\section{DEFINITIONS/ABBREVIATIONS}

\section{CVS}

Constant Volume Sampler

DMS

Differential Mobility Spectrometer

\section{DPF}

Diesel Particulate Filter

FAME

Fatty Acid Methyl Ester 
Federal Test Procedure

GC

Gas Chromatograph

\section{NEDC}

New European Drive Cycle

\section{PAH}

Poly-Aromatic Hydrocarbon

\section{PCM}

Powertrain Control Module

PM

Particulate Mass

PN

Particle Number

\section{RME}

Rapeseed Methyl Ester

SPCS

Solid Particle Counting System

T50

Temperature at which $50 \%$ of the volume has been recovered 